\title{
Junctional epidermolysis bullosa-pyloric atresia syndrome
}

INSERM

\section{Source}

INSERM. (1999). Orphanet: an online rare disease and orphan drug data base. Junctional epidermolysis bullosa-pyloric atresia syndrome. ORPHA:79403

Junctional epidermolysis bullosa with pyloric atresia is a severe subtype of junctional epidermolysis bullosa (JEB, see this term) characterized by generalized blistering at birth and congenital atresia of the pylorus and rarely of other portions of the gastrointestinal tract. 